\title{
Smoking cessation in Brazil: a survival analysis based on consumers' profile
}

\author{
Cessação do hábito de fumar no Brasil: \\ uma análise de sobrevivência baseada no perfil dos consumidores
}

Camila de Moura Vogt (https://orcid.org/0000-0002-5693-9637) ${ }^{1}$

Adelar Fochezatto (https://orcid.org/0000-0001-7192-3986) ${ }^{2}$

Augusto Mussi Alvim (https://orcid.org/0000-0003-0130-6880) ${ }^{2}$

${ }^{1}$ Faculdade de Economia,

\begin{abstract}
Cigarette consumption is a worldwide epidemic and its reduction is one of the major public health concerns. In Brazil, although there is a wide literature on smoking cessation it is restricted to experimental studies. Based on data from the 2013 National Health Survey (PNS), this study uses the survival methodology and use population data and consumer's profile to investigate which characteristics will affect smoking cessation hazard. The results showed that the people who are less likely to quit smoking are older, single men, with low income and fewer education years. They also do not practice physical exercise. The findings of cigarette cessation hazard to Brazilian population are similar of experimental studies with smokers and ex-smokers in country. Therefore, in order to decrease public health spending, Brazilian health policies regarding tobacco cessation could focus on those groups who will likely smoke for a long time.
\end{abstract}

Key words Survival analysis, Smoking cessation, PNS, Brazil, Tobacco
Resumo O consumo de cigarro é uma epidemia mundial e sua redução é uma das principais preocupações de saúde pública. No Brasil, embora exista uma ampla literatura sobre a cessação do tabagismo, ela se restringe a estudos experimentais. Com base nos dados da Pesquisa Nacional de Saúde de 2013 (PNS), este estudo usa a metodologia de sobrevivência e usa dados da população e os perfis dos consumidores para investigar quais características afetarão as chances de cessação do tabagismo. Os resultados mostraram que as pessoas com menor probabilidade de parar de fumar são homens mais velhos e solteiros, com baixa renda e menos anos de estudo, que não praticam exercícios físicos. Os achados do risco de cessação do cigarro para a população brasileira são semelhantes a estudos experimentais com fumantes e ex-fumantes no país. Portanto, para diminuir os gastos em saúde pública, as políticas de saúde brasileiras em relação à cessação do tabaco poderiam se concentrar nos grupos que fumarão por mais tempo.

Palavras-chave Análise de sobrevivência, Cessação de fumo, PNS, Brasil, Tabaco (acheral do

Pará. R. Augusto Corrêa 111, Guamá, 66073-040. Belém

PA Brasil.

camilavogt@ufpa.br

${ }^{2}$ Programa de Pós-

Graduação em Economia,

Pontifícia Universidade

Católica do Rio Grande do

Sul. Porto Alegre RS Brasil. 


\section{Introduction}

Evidence that smoking is harmful to health has made most countries adopt tobacco control measures. The Framework Convention for Tobacco Control (FCTC) is the most important world tobacco control agreement developed by WHO between 1999 and 2003. It brought together 192 countries to regulate tobacco consumption worldwide with measures covering health and environmental problems. Among the proposed measures, the FCTC stimulates health treatment, health warnings, the adoption of more control and restrictions on advertising, illegal trade and prices. Brazil was one of the leaders in the creation of the FCTC, which entered into force in the country in February 2005.

According to Portes et al. ${ }^{1}$, between 2011 and 2015 , there were advances in regulation of tobacco products in legislation related to the promotion of smoke-free environments and warnings on cigarette packs and prices. Despite the advance in tobacco control in Brazil, smoking continues to be a serious public health concern in the country, with impressive numbers related to morbidity, mortality, and public health care costs.

The Brazilian cigarette consumers' profile from the 2008 Brazilian National Household Sample Survey (PNAD in Portuguese) shows that consumption is higher among individuals who are in the lowest decile of income $e^{2,3}$. The public that is more dependent on the governmental health system, accounting for higher public expenditure on health. The prevalence of smoking is higher among men $18.8 \%$ than among women $(11.6 \%)$. Age has a positive impact on the prevalence of smokers until the age of 59, and daily consumption has an inverse relationship with income. Based on statistical data concerning students and cigarettes in Brazil, most smokers are in families those making under four minimum wages, and about $64 \%$ of them are lower educat$\mathrm{ed}^{2}$. In Bazotti et al. ${ }^{4}$, based on analysis of Brazil's Family Budgets Survey (POF, in Portuguese) of 2008-2009, tobacco consumers are older, earn low salaries and have less schooling than someone who does not consume tobacco. Authors also reinforces that knowledge about the population that consume tobacco products can increase the efficacy of more specific policies.

Research shows that about $80 \%$ of smokers want to quit, however, only $3 \%$ do it each year, and most of this group quit without help ${ }^{5}$. It is known that biological and genetic issues con- tribute to cigarette addiction. However, this interpretation does not exclude the interference of other factors in the behavior of smoking. In Brazil, several experimental studies have evaluated the characteristics of smokers who try to quit. Studies have indicated that there is a relationship with the chances of successful smoking cessation, related to gender, age, education, financial status and health characteristics ${ }^{7-13}$.

In a smoking cessation program with 159 individuals conducted between 2003 and 2004 Luppi, Alves and Santos ${ }^{7}$ indicate the inverse relationship between smoking prevalence and education. It emphasizes that low education influences treatment as it makes it difficult to understand the written content presented. In addition, the financial situation appears as a relevant aspect in choosing the treatment to be used, which ends up influencing the chances of success when quitting smoking. It also concludes that the proportion of smokers in the most dependent groups progressively increases in older age groups (between 51 and 60 years), which makes attempts to quit smoking difficult. Silva et al. ${ }^{8}$ in a study with 629 smokers, concludes that the highest rates of smoking cessation were observed among younger and older individuals, which have been associated with a higher prevalence of smoking cessation in other studies.

Lombardi et al. ${ }^{9}$, that evaluated 203 smokers served by the Prevention and Smoking Cessation Support Center (PrevFumo, in Portuguese) of the Federal University of São Paulo from January 2002 to May 2003, highlights issues related to gender and smoking cessation. Factors related to the greater difficulty of quitting smoking among the female population can be cited, such as a higher prevalence of depression, stress related to double working hours, a difficulty in maintaining weight in attempts to quit and also a finding of that women feel safer smoking in difficult or sad situations. However, women have a greater search for smoking cessation programs associated with easier recognition of health care difficulties and the request for specialized help. Castro, Matsuo and Nunes ${ }^{10}$, in a study of 167 people enrolled in a smoking cessation program at the State University of Londrina Tobacco Treatment Reference and Approach Center, also identified the relevance of gender issues in the chances of treatment. The study also states that women are more concerned about health problems, especially cancer, which increases their chances of treatment.

The prevalence of alcohol dependence, as concluded by Nunes et al. ${ }^{11}$ is another feature 
that can influence the tobacco addiction. It is about four times higher among people with tobacco dependence than in the rest of the population. In addition, psychiatric problems such as the diagnosis of depression also increase rates of tobacco cessation failure ${ }^{7,8,10}$. Other chronic health problems such as diabetes, hypertension, heart disease, respiratory disease and peptic ulcer, are significantly higher in people who smoked $^{10}$. Characteristics such as marital status can also contribute to how people respond to smoking regulation ${ }^{12}$. Married people are more conducive to smoking bans in all public areas except for closed workplaces, while those who were married before are more pro-ban restaurants and less ban-prohibitive in closed workplaces. Additionally, effects of gender, family income, and education vary by type of regulation.

According to Balbani and Montovani ${ }^{13}$, it is difficult to compare the results of various scientific studies on smoking cessation efficacy. Many factors need to be taken into account: the cultural and socioeconomic characteristics of the patients, the reasons that led them to participate in the smoking cessation program, the degree of nicotine dependence, the follow-up time and the criteria used to evaluate treatment success (objective or subjective).

Douglas and Hariharar ${ }^{14}$ mentioned, two different models analyze the consumption of addictive goods such as cigarettes: the "rational" and the "irrational" model. However, testing the behavioral predictions of these models was primarily restricted to experimental studies. To use consumer data, behavior studies about smoking have applied the duration model methodology to population data ${ }^{14,15}$. The duration models are based in survival analysis with econometric modeling data ${ }^{16}$. The results suggest that education, age, and more financial planning have positive effects on quitting hazards. In other words, it is possible to state that more educated people, older and with better financial planning have more chance of quitting smoking.

In Brazil there is a gap in population data studies on smoker'sbehavior. Thus, the possibility of comparing the results with representative analyzes of the Brazilian population, such as that presented by the National Health Survey (PNS, in Portuguese), is the main objective of this work. For this, it will use econometric models based on survival methodologies or duration models.

\section{Methodology}

Based on population data from the 2013 National Health Survey (PNS) ${ }^{17,18}$ rather than experimental studies, it investigates the characteristics that affect smoking duration. The study applied the methodology of Kaplan-Meier survival analysis to characteristics, which were then evaluated according to the Cox likelihood model. Duration models, or survival models associated with econometrics, are widely used as models for analyzing behavior in the economy. The use of this method is justified by the fact that the models allow the use of transversal data (such as the PNS). The methodology aims at classifying the features of the hazard rate over smoking duration, i.e. those that affected the hazard of quitting tobacco product use.

The 2013 National Health Survey(PNS) is a nationwide cross-sectional home-based survey that has a periodicity of 5 years. The sampling is stratified in three stages of conglomeration ${ }^{17}$. The census sectors were the primary sampling units; households, second-stage units; and adult residents (18 years or older), third-stage units. Information was collected in 64,348 households. In each household, an adult resident aged 18 years or older was selected by simple random sampling and, in total, 60,202 individuals were interviewed. It comprises three questionnaires: the domicile, referring to the characteristics of the domicile; the one related to all the residents of the domicile; and the individual, to be answered by a domicile resident of 18 years of age or more.

In order to analyze whether the characteristics studied influenced smoking, one estimates smoking duration. In this study, it was calculated based on age of smoking on set, current age and how long it took the subject to quit smoking. Thus, duration of smoking is calculated based on the individual age, the age at which he started smoking and how long ago he stopped smoking, if he stopped (PNS variables: c008, p053 and p05901, respectively) (Table 1). For example, a 30 -year-old person who starts smoking at the age of 20, but has not smoked for 3 years, has a duration of 7 years.

A total of 15,501 observations from people who report the age they started smoking daily were selected (303 observations were exclude in reason of survival time negative or less than 1 year), among which 7,974 are still smokers and were therefore censored. This censoring is called right-censored, which occurs when the study ends before the studied episode ends (smoking 
Table 1. Descriptive statistics of PNS daily smokers.

\begin{tabular}{|c|c|c|c|}
\hline \multirow{2}{*}{ Attribute } & \multirow{2}{*}{ Description } & \multicolumn{2}{|c|}{$\%$} \\
\hline & & Smokers & Ex-Smokers \\
\hline \multirow[t]{7}{*}{ Age } & 18 to 27 & 12.7 & 5.5 \\
\hline & 28 to 37 & 21.1 & 12.7 \\
\hline & 38 to 47 & 21.5 & 17.2 \\
\hline & 48 to 57 & 24.2 & 22.9 \\
\hline & 58 to 67 & 13.6 & 22.2 \\
\hline & 68 to 77 & 5.5 & 13.7 \\
\hline & More than 78 & 1.6 & 5.9 \\
\hline \multirow[t]{2}{*}{ Gender } & Male & 57 & 54 \\
\hline & Female & 43 & 46 \\
\hline \multirow[t]{5}{*}{ Race } & White & 36 & 41.3 \\
\hline & Black & 11.6 & 9 \\
\hline & Yellow & 0.8 & 0.9 \\
\hline & Brown & 50.7 & 48.1 \\
\hline & Indigenous & 0.8 & 0.8 \\
\hline \multirow[t]{3}{*}{ Marital Status } & Married & 30.3 & 46.2 \\
\hline & Divorced/Separate or widowed & 17.3 & 21.8 \\
\hline & Single & 52.4 & 32.0 \\
\hline \multirow[t]{6}{*}{ Education } & Literacy/ Initial grades & 15 & 16 \\
\hline & Fundamental School & 50 & 49 \\
\hline & High School & 24 & 22 \\
\hline & University & 10.8 & 12.5 \\
\hline & Master & 0.5 & 0.6 \\
\hline & Doctorate & 0.2 & 0.3 \\
\hline \multirow[t]{3}{*}{ Income } & Less than $\mathrm{R} \$ 441.00$ & 26.7 & 19.4 \\
\hline & From $\mathrm{R} \$ 441.00$ to $\mathrm{R} \$ 1,019.00$ & 40.3 & 40.1 \\
\hline & More than R\$1,019.00 & 33 & 40.5 \\
\hline \multirow{2}{*}{$\begin{array}{l}\text { Alcohol } \\
\text { consumption }\end{array}$} & Do not consume alcoholic beverages & 40.2 & 62.8 \\
\hline & Consume alcoholic beverages & 59.8 & 37.2 \\
\hline \multirow[t]{2}{*}{ Physical Exercises } & Practiced exercises in last three months & 20.5 & 27.2 \\
\hline & Did not practice exercises in last three months & 79.5 & 72.8 \\
\hline \multirow[t]{2}{*}{ Hypertension } & Have been diagnosed & 19.8 & 34.5 \\
\hline & Have not been diagnosed & 80.2 & 65.5 \\
\hline \multirow[t]{2}{*}{ Lung Diseases } & Have been diagnosed & 2.6 & 3.2 \\
\hline & Have not been diagnosed & 97.4 & 96.8 \\
\hline
\end{tabular}

Source: Authors, based on data from the 2013 PNS/IBGE.

cessation in this case) or when the subject is withdrawn from the sample ${ }^{19}$. Thus, the analysis considers only the behavior and habits of people above 18 years old and residents in permanent private households that report the age that start smoke cigarettes daily.

Considering that a simple random sample is made of a resident in the household, it is natural that, due to the randomness of the selection, the totals of the population obtained with the expansion factors of the selected resident are not exactly equal to the totals of the population obtained with the factors of expansion of the house. However, according to the PNS sample design ${ }^{17}$, household residents are a much larger sample than the selected residents and, therefore, a more accurate estimate of these population totals. Thus, respondents respond significantly to the smoking prevalence indicator in Brazilian households over 18 years that smoke daily. It should be noted, however, that the calculation of whether or not to remain in the habit of smoking con- 
siders only people who effectively quit smoking, those who quit smoking and return to smoking are right-censored.

The study variables were chosen consideringthe results of experimental studies describe in next section. It is separate in four big areas: social profile, education, income, and health habits. Age, gender, race, and marital status were used to analyze social profile. In the health habits category, lung disease, hypertension, exercising, and alcoholic beverage consumption were analyzed.

\section{Statistical analysis}

\section{Smoking time survival analysis: Kaplan-Mayer}

The Kaplan-Mayer analysis survival method was used to study the characteristics of cigarette consumption. Survival analysis is commonly used in health research to assess the impact of medications on certain diseases ${ }^{19}$. However, it has also been used in analyses of such social issues as unemployment, and social policies s,21,22 $^{2}$.

In the estimate of smoking survival habit, $t$ is the total of years reported by the oldest person, and each observation of smoking time is considered until failure, or the event of smoking cessation. The people who have not stopped smoking are censored in the analysis because they do not have the event of failure, i.e. smoking cessation.

Thus, a survival analysis will consider two variables as a function of time, survival function and hazard function. The survival time $t$ can be defined as a random positive variable with probability distribution $F(t)$ (equation 1 ) and the density probability function $f(t)$ (equation 2 ).

$$
\begin{aligned}
& F(t)=P(T \leq t) \\
& f(t)=\frac{P(t \leq T<t+\Delta t \mid T)}{\Delta t}
\end{aligned}
$$

The function $S(t)$ or survival will respond to the probability that an event $\mathrm{P}$ will survive more than a specific time $t$ when compared to a given time $T, S(t)=P(T>t)$ or $S(t)=P(T>t)=1$ $F(t)$.

Theoretically, while $t$ varies from 0 to infinity, the survival function can be represented as a smooth curve. For the survival analysis the most used method is Kaplan-Meier (KM), defined by equation 3, where $N$ is the total of individuals in which survival time is available and $r$ corresponds to the positive integers for which $t_{n} \leq t$.

$$
S(t)=\Pi \frac{(N-r)}{(N-r+1)}
$$

The hazard function, denoted by $h(t)$, is given by equation 4 , which describes the instantaneous potential per unit time for the event to occur since it survived beyond time $t$. In contrast to the survival function, which focuses on not failing, the risk function focuses on failure, that is, the event elapses. Thus, in some sense, the risk function can be considered as providing the opposite side of the information given by the survival function or the $f(t)$ divided by $S(t)$.

$$
\mathrm{h}(\mathrm{t})=\frac{P(t \leq T<t+\Delta t \mid T \geq t)}{\Delta t}
$$

The log-rank chi-square test is used for large samples to compare different survival curves using KM. This statistical test, as well as others applied to KM curves, use observed versus expected observations in the categories analyzed. The categories for log-rank statistics are defined by each of the failure times ordered for the entire set of data analyzed. The study used the method for the selection of variables that influence smoking duration. The testing method evaluates whether or not KM curves for two or more groups are statistically equivalent. Considering that there is difference between the smoking duration, it is estimate the hazard function for each selected variable, or the hazard of smoking cessation.

\section{The smoking cessation hazard: Cox model}

There are different models for the study of survival analysis. One of the most used semi-parametric models is the Cox proportional hazard model, which uses the maximum likelihood method to estimate risk ratio. It provides the adjusted survival curves and the meaning of the proportional risk assumption. The Cox model estimates proportional failure rates according to equation 5 . The vector $X$ with $p$ covariates, $\beta$ the vector with $p$ unknown parameters, and $\alpha(X)$, the failure rate function.

$$
\alpha(X)=\alpha_{0}(t) \exp \left\{X^{\prime} \beta\right\}
$$

The main assumption of the model is the proportionality of the risk between the individuals, whose ratio is constant over time. Thus, the risk of an individual is any multiple of the risk function of any other individual, and the factor is the risk ratio $e^{\beta(x 1+x 2)}$ being $x_{1}$ an individual 
who does not receive the treatment and $x_{2}$ the one who receives it. To validate the suitability of the model, it is necessary to test the hypothesis of proportional risks, which can be done by graphical approach or by the Statistical test of the Schoenfeld residuals ${ }^{23}$.

The study used the statistical program to data analysis Stata 12.0 and the commands ststo generate graphs, lists, and test the survivor and $\mathrm{cu}-$ mulative hazard functions.

\section{Results}

Figure 1 (A) shows duration of smoking, with the minimum period of cigarette consumption being one year, the maximum, 81 years, and the average duration 22 years. The survival curve shows a typical mild decline as time increases. Table 2 shows the log-rank test results, and the Figure 1 (B) to (J)duration of smoking, considering each variable analyzed. In the analysis, "race" did not present significant results ( $\mathrm{p}=$ value 0.358$)$. In other words, the KM curves for the groups are statistically equivalent, or there is no significant difference between the survival curves (Figure 1 (C)). The other variables, however, showed significant results and indicate different smoking duration in the sample.

By analyzing smoking curves, the study estimated the hazard of smoking cessation. As discussed previously, $\alpha(X)$ gives an estimated hazard ratio for the effect of each variable. Thus, the study analyzed each item in order to verify the duration of smoking. Some characteristics were evaluated as dummies; so, for the smoking cessation hazard ratio, $\alpha(X=1) / \alpha(X=0)=e^{\beta}$. In other words, if $e^{\beta}$ is 0.9 , for example, the hazard ratio of the group $(X=1)$ is $10 \%$ lower than the other group $(X=$ $0)$. Hence, the result is positive when the hazard rate is more that $100 \%$, which indicates that the group will be more likely to quit smoking. For continuous variables: $\alpha(X+1) / \alpha(X)=e^{\beta}$; so, for an increase of 1 unit (month, day, year ...) in the variable, the failure rate is multiplied by $e^{\beta}$. If $e^{\beta}=$ 1.20 , the same increase in the variable increases by $20 \%$ the chances of smoking cessation.

The results of Table 3 and Figure 2 show the estimate in the semi-parametric Cox model. In Table 3 the first column represents the exogenous coefficients whereas the second shows coefficient $\beta$ and the third, the hazard ratio $e^{\beta}$. To the results analysis it considers as significance at least 95\% of confidence in chi-squared test.
Age has a negative impact on smoking cessation hazard, which is a negative result, considering that each year of increased age decreases the probability of smoking cessation by $6.6 \%$. Thus, younger people have a higher probability of smoking cessation when compared to older ones. Considering that the addiction starts at age 17 on average, the longer it persists, the lower the chances of cessation.

Females are the ones with more hazard of smoking cessation: about $6 \%$ more than the men. When it comes to marital status, single people have from $14 \%$ to $4 \%$ fewer chances to stop smoking, compared to those of married people. The result was not significant for the divorced, separated or widow(er).

More years of education will significantly result in mores chance of smoking cessation. The chances of those who have the first level of secondary education and those with tertiary education are respectively $21 \%$ and $34 \%$ higher than those with a lower education level. Taking into account income levels, the marginal effect is negative. An increase of one unit decreases the hazard of smoking cessation by $6 \%$. Richer people, therefore, have are more likely to quit smoking.

Concerning health habits, the consumption of alcoholic beverages was not significant. Practicing physical exercises, however, increases the chance of smoking cessation, whereas not exercising decreases it by $24 \%$. Not having pulmonary problems also had a significant negative impact: $36 \%$ more chances of quitting. Hypertension, however, was not significant.

Thus, according to the results, the people who are less likely to quit smoking are older, single men with low income and little education. They do not exercise and have pulmonary diseases.

In the PNS sample, several individuals have a start in different periods, thus the hypothesis of proportional hazards assumed by the Cox regression model is confirmed by the Schoenfeld test. It tests the proportionality of risks between the groups, which was not rejected at $1 \%$ significance $($ Prob $>$ chi-squared $=0.927)$. As a result, the main requirement for the Cox model was satisfied, which has validated the findings of the regression.

\section{Discussion}

The estimate of KM curves to study smoking duration differences was significant for all charac- 

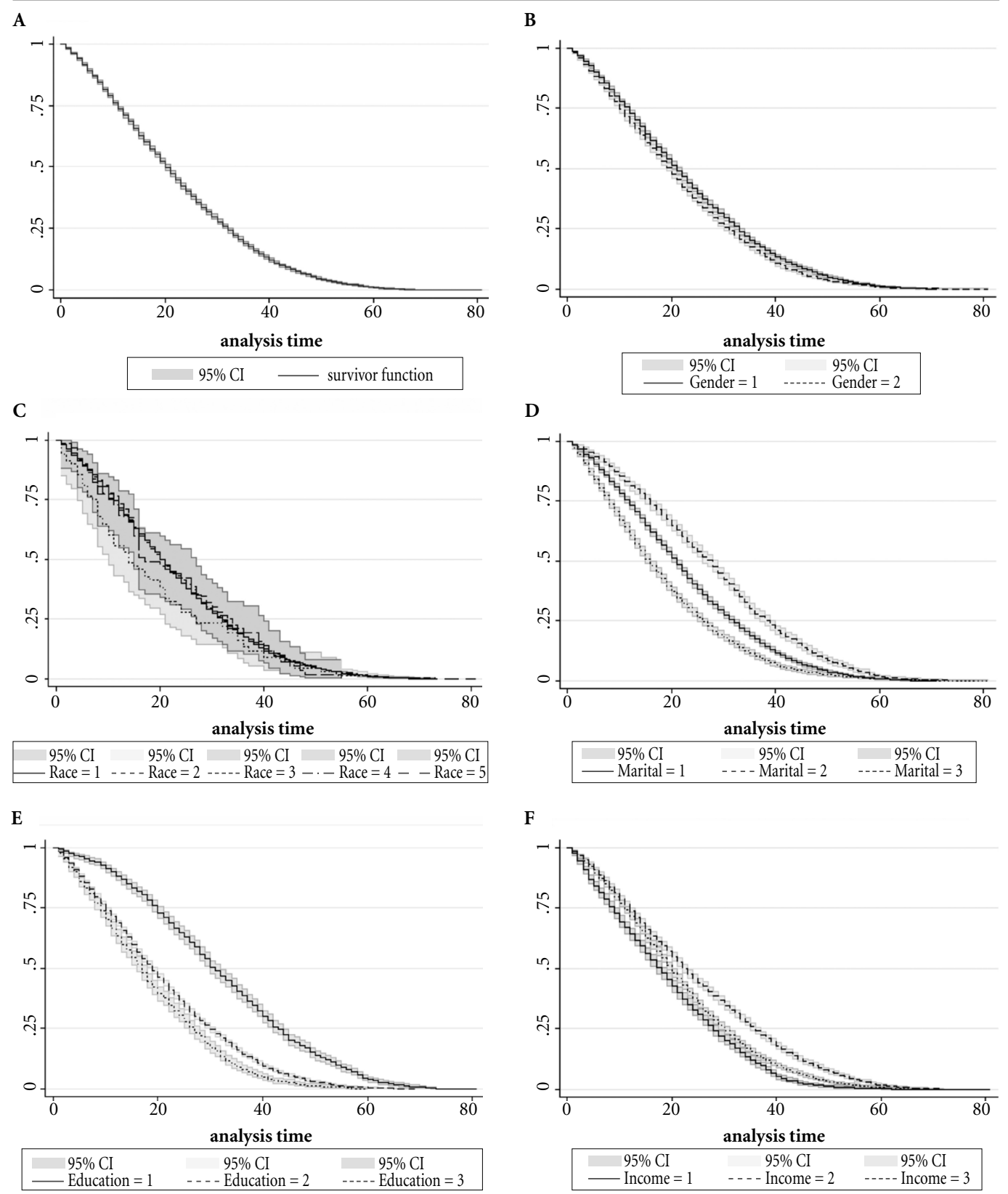

it continues

Figure 1. Kaplan-Meier analyses of cigarette consumption (A) Smokers from PNS (2013). (B) Gender. (C) Race. (D) Marital Status. (E) Education. (F) Income (G) Alcohol Consumption. (H) Physical Exercise. (I) Hypertension Diseases. (J) Pulmonary Diseases.

Source: Author's elaboration.

teristics except race. Thus, the hazard of smoking cessation was estimated using the semi-parametric model Cox. According to the results, those with more hazard of quitting are younger, married women, with high income and education, who exercise and do not have any pulmonary disease. The findings converge with experimental studies conducted on different groups of people trying to quit smoking.

Considering the age distribution of smokers, the results corroborate the importance of health campaigns for the youth to raise awareness about 

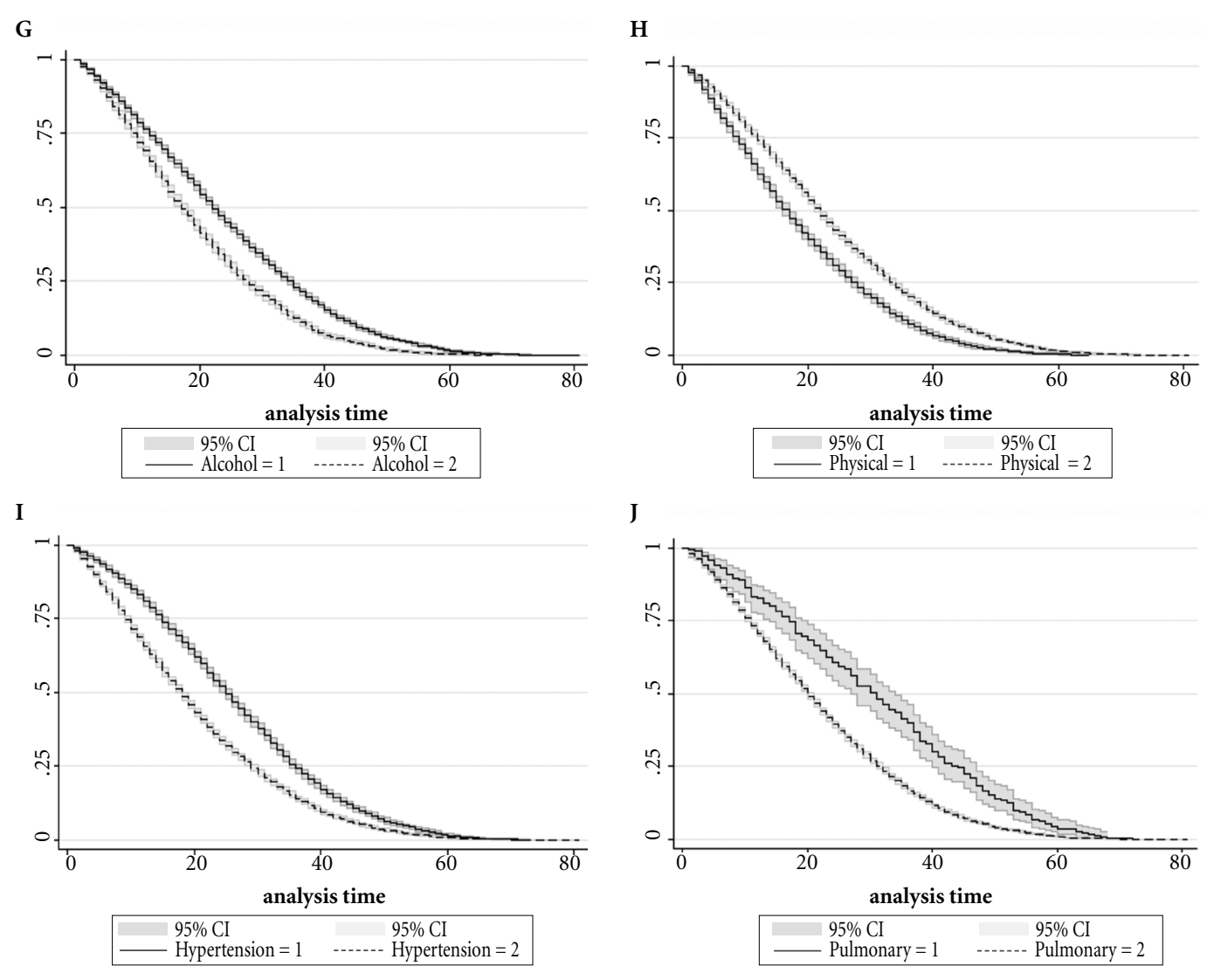

Figure 1. Kaplan-Meier analyses of cigarette consumption (A) Smokers from PNS (2013). (B) Gender. (C) Race. (D) Marital Status. (E) Education. (F) Income (G) Alcohol Consumption. (H) Physical Exercise. (I) Hypertension Diseases. (J) Pulmonary Diseases.

Software Stata 2012.

Source: Author's elaboration.

Table 2. Log-rank results for the selected variables of ex-smokers from the PNS (2013).

\begin{tabular}{|c|c|c|}
\hline Attribute & $\chi^{2}$ & P-value \\
\hline Age & 6805.60 & $0.000^{\star *}$ \\
\hline Race & 4.37 & $0.358 \ldots$ \\
\hline Gender & 18.49 & $0.000^{* *}$ \\
\hline Marital Status & 358.03 & $0.000^{* *}$ \\
\hline Education & 545.27 & $0.000^{* *}$ \\
\hline Income $e^{\star * *}$ & 200.96 & $0.000^{* *}$ \\
\hline Alcohol Consumption & 214.89 & $0.000^{* *}$ \\
\hline PhysicalExercise & 182.68 & $0.000^{* *}$ \\
\hline Hypertension & 214.66 & $0.000^{* *}$ \\
\hline LungDiseases & 64.32 & $0.000^{* *}$ \\
\hline
\end{tabular}

how harmful smoking is. Further, the findings of experimental researches concurs about the greater chances of failure of smoking cessation for older smokers ${ }^{7,8}$.

With respect to gender, smoking duration is shorter for women and they have more chances to stop smoking (Figure1 (B)). It corroborates with the results of increased treatment participation and the success of smoking cessation for women $^{9,10}$. Although significant, however, the CI of the female is very close to 1 (Figure 2) from $0.006 \%$ to $11 \%$. Thus, it is important to stress that the different of consumer behavior of male and females smokers do not present a great difference.

Regarding marital status, single people are the majority in the smoker samples and their 
Table 3. Cox estimates:coefficient and hazard ratiofor smoking cessation of the PNS (2013).

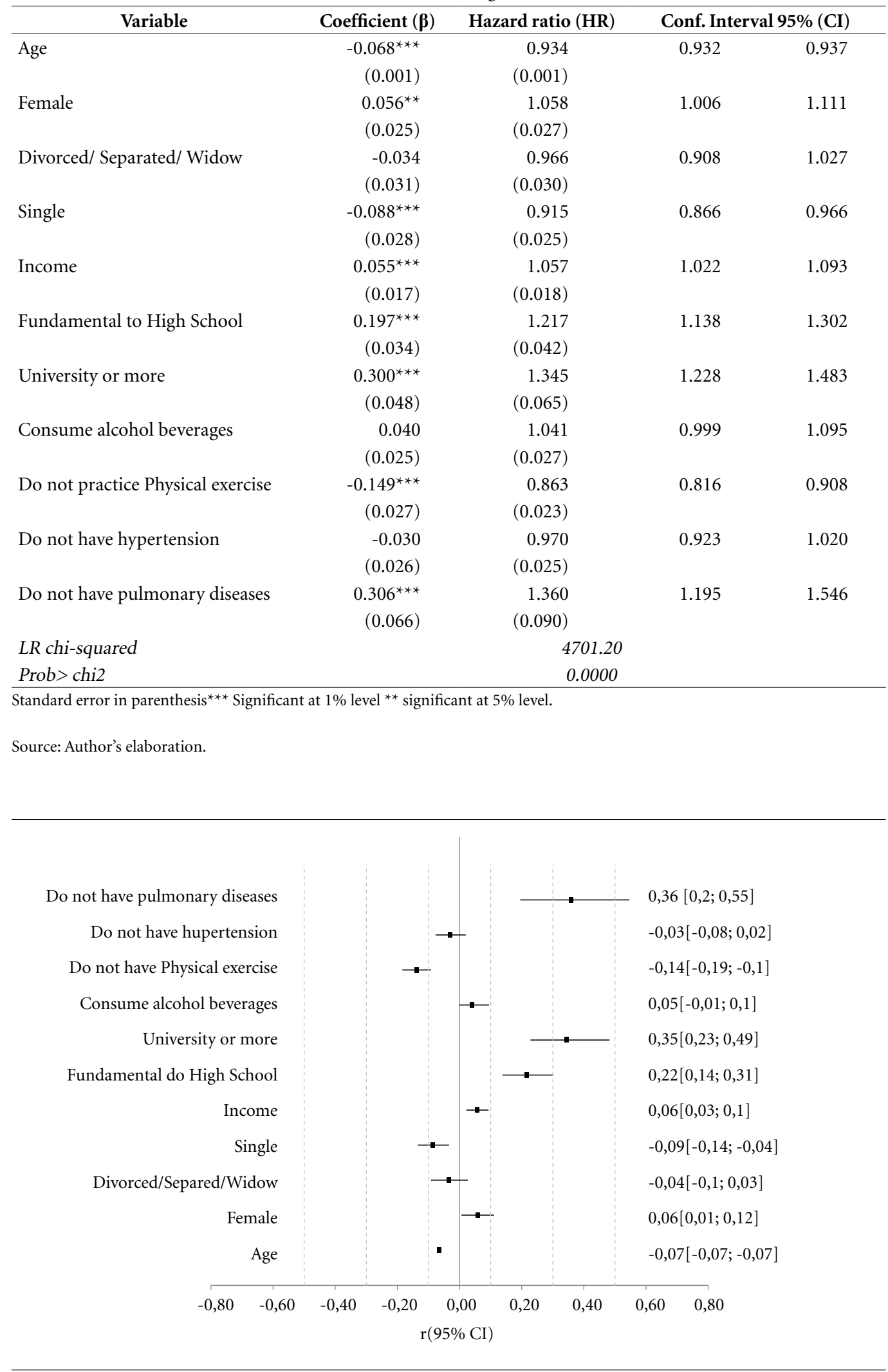

Figure 2. Hazard ratio forest plot: Cox estimates results for smoking cessation of the PNS (2013). 
chances to stop smoking are significantly lower than that of married ones (Figure1 (D)). The findings had already been presented in studies about the difference responses to smoking regulation ${ }^{11}$. Separated/divorced/widow(er) people have a longer duration of smoking compared to that of married and single ones, but their chances of quitting the habit are not significantly different.

Education presented the greatest hazard to quit smoking (Figure $1(\mathrm{E})$ ). Thus, longer education had a high impact on smoking cessation, which corroborates studies about smoking in Brazil and abroad ${ }^{7,8,9,10}$. The recent increase in education in the country can also account for the decrease in the number of smokers; however, this cause needs further studies.

When it comes to income, most of the people who stopped smoking are in richest range ${ }^{2,3}$. The fact that income guarantees access to better smoking cessation treatments, according findings in experimental studies contributes to the conclusion ${ }^{7,9}$. The increase in income has a negative impact on the hazard of smoking cessation. In other words, the higher the income, the higher the chances to stop smoking. However, the survival curves have shown a longer smoking duration for middle-income people and a shorter duration for low-income (Figure 1 (F)). Although there is no evidence in experimental studies about the Brazilian consumption, the price increase effect is an important tool in tobacco control. Studies indicate that a price increase of $10 \%$ can reduce tobacco products consumption by $5 \%$ in low and middle-income countries ${ }^{26}$. Thus, as lower-income population is more price sensitive and it can reduce the duration of tobacco consumption $^{27}$. Therefore, although income has a positive effect in cessation hazard, the effect can be different for different income distributions. However, a more detailed analysis of socioeconomic distributions deserves more research in future.

Habit-related characteristics reinforce the importance of healthy activities in order to quit smoking ${ }^{10,11}$. People who exercise had high chances of smoking for a shorter time (Figure $1(\mathrm{H})$ ). Alcohol consumption, however, is not significant for the chances of quitting smoking and the duration of smoking is shorter for people who con- sume alcohol (Figure $1(\mathrm{G})$ ). Although studies indicate that alcohol consumption is associated with smoking ${ }^{7,8,10,11}$ the results can be explained because it is not possible to identify the level of consumption which can affect the relationship between alcohol and cigarettes in PNS. The study compares a sample of people who never consume alcohol to individuals who consume less than once a month or have daily consumption. Thus, in the same way as the income variable, alcohol consumption needs a more detailed analysis in future studies.

Regarding diseases, although those who do not have pulmonary ones have higher chances of smoking less, the presence of hypertension was not significant for the risk of smoking cessation (Figure 1 (I)). The result may be associated with the lack of information from smokers about the relationship between non-pulmonary diseases and cigarette consumption (Figure $1(\mathrm{~J})$ ). However, it is necessary to explore whether the same behavior applies to other chronic diseases ${ }^{10}$.

The classification of the results showed that the variables related to lung diseases, education, and physical exercise, have the greatest impact on the chances of quitting smoking. Subsequently, we have marital status, age, sex and income. The results represent important insights into the importance of topics related to health information and education in tobacco control.

It also should be noted that the econometric methods used are based only in on the probabilities and density function of the sample, being a plausible way to model consumer behavior within the studied sample. It is important to emphasize that the analyses are based on current characteristics; thus, some could be different at the point of smoking cessation. For that reason, further studies considering different cohorts of smoking cessation could improve the validity of the results.

Through the analysis of the characteristics involving smoking in Brazil, one can conclude that some social and economic characteristics can hinder or facilitate the implementation of smoking-control policies and smoking cessation treatments in the country. Even with a reduction in the number of smokers, smoking duration and the onset of the habit among the youth are an alert to the long-term efficacy of such policies. 


\section{Collaborations}

CM Vogt was responsible for the design, planning, database organization, estimations, analysis, interpretation, and writing of the article. A Fochezatto performed the conception, planning, analysis, and interpretation of the work. AM Alvim performed the analysis and interpretation, supervision, and writing of the work. All authors agreed to be accountable for the content of the work.

\section{References}

1. Portes LH, Machado CV, Turci SR. Trajetória da política de controle do tabaco no Brasil de 1986 a 2016. Cad Saude Publica 2018; 34(2):1-20.

2. Zanini RR, Moraes AB, Trindade AC, Riboldi J, Medeiros LR. Prevalência e fatores associados ao consumo de cigarros entre estudantes de escolas estaduais do ensino médio de Santa Maria, Rio Grande do Sul, Brasil. Cad Saude Publica 2006; 22(8):1619-1627.

3. Barros AJD, Cascaes AM, Wehrmeister FC, MartínezMesa J, Menezes AMB. Tabagismo no Brasil: desigualdades regionais e prevalência segundo características ocupacionais. Cien Saude Colet 2011; 6(9):3707-3716.

4. Bazotti A, Finokiet M, Conti IL, França MTA, Waquil PD. Tabagismo e pobreza no Brasil: uma análise do perfil da população tabagista a partir da POF 20082009. Cien Saude Colet 2016; 21(1):45-52.

5. Instituto Nacional de Câncer (INCA). Abordagem e Tratamento do Fumante. Consenso 2001; 1(1):1-38.

6. Rondina RC, Gorayeb R, Botelho C. Características psicológicas associadas ao comportamento de fumar tabaco. J Bras Pneumol 2007; 33(5):592-601.

7. Luppi HCB, Virgínia M, Faria M, Alves F. Programa de cessação ao tabagismo: perfil e resultados. Revist Cien Extens 2006; 2(2):1-18.

8. Silva RLF, Carmes ER, Schwartz AF, Blaszkowski DS, Cirino RHD, Ducci RDP. Cessação de tabagismo em pacientes de um hospital universitário em Curitiba. $J$ Bras Pneumol 2011; 37(4):480-487.

9. Lombardi EMS, Prado GF, Santos UP, Fernandes FLA. O tabagismo e a mulher: riscos, impactos e desafios. $J$ Bras Pneumol 2011; 37(1):118-128.

10. Castro MRP, Matsuo T, Nunes SOV. Características clínicas e qualidade de vida de fumantes em um centro de referência de abordagem e tratamento do tabagismo. J Bras Pneumol 2010; 36(1):67-74

11. Nunes SOV, Castro MRP, Castro MSA. Tabagismo, comorbidades e danos à saúde. Tabagismo Abordagem Prevenção Trat 2011:17-38.

12. Hersch J. Smoking Restrictions as a Self-Control Mechanism. J Risk Uncertainty 2005; 31:5-21.

13. Balbani APS, Montovani JC. Métodos para abandono do tabagismo e tratamento da dependência da nicotina. Rev Bras Otorrinolaringol 2005; 71(6):820-826.

14. Douglas S, Hariharar G. The hazard of starting smoking: estimates from a split population duration model. J Health Economics 1994; 13(2):213-230.

15. Kuo YP. Determinants of Smoking Cessation [dissertation]. Netherlands: Tilburg University Master of Econometrics and Mathematical Economics; 2013.

16. Kiefer N, Kiefer N. Economic Duration Data and Hazard Functions. J Economic Literature 1988; 26(2):646679.

17. Instituto Brasileiro de Geografia e Estatística (IBGE). Pesquisa Nacional de Saúde 2013. [acessado 2018 jul 21]. Disponível em: http://www.pns.icict.fiocruz.br/

18. Instituto Brasileiro de Geografia e Estatística (IBGE). Microdados do Pesquisa Nacional de Saúde 2013. [acessado 2017 jul 21]. Disponível em: http://www.ibge. gov.br/home/estatistica/populacao/pns/2013/default. shtm

19. Lee E, Wang J. Statistical Methods for Survival Data Analysis. $3^{3}$ Edition. Nova Jersey: John Wiley\& Sons, Inc; 2003. 
20. Taylor MP. Survival of the fittest? An analysis of self-employment duration in Britain. The Economic $J$ 1999; 109:14-155.

21. França MTA, Saccaro A. Gastos governamentais no Ensino Superior e evasão: um estudo de análise de sobrevivência para os estudantes dos cursos de ciências naturais e engenharias em instituições públicas e privadas. Encontro Nacional de Economia; 2016. [acessado 2018 jul 21]. Disponível em: https://www.anpec. org.br/encontro/2016/submissao/files_I/i5-9730f61c6dd889108f42eb81f727b9b9.pdf

22. Conceição OC, Saraiva MV, Fochezatto A, França MTA. O Simples Nacional e a longevidade das empresas industriais: uma análise de sobrevivência a partir dos microdados da RAIS. Confederação Nacional da Indústria 2016. [acessado 2017 jul 21]. Disponível em: http://arquivos.portaldaindustria.com.br/app/conteudo_18/2016/11/29/12364/o_simples_nacional_e_ as_empresas_industriais_uma_analise_de_sobrevivencia_a_partir_dos_microdados_da_rais.pdf

23. Schoenfeld D. Partial residuals for the proportional hazards regression model. Biometrika 1982; 69(1): 239-241.

24. Gail M, Krickeberg K, Samet JM, Tsiatis A, Wong W. Statistics for Biology and Health Series Editors. $3^{\mathrm{a}}$ Edition. Atlanta:Springer; 2012.

25. Secretaria de Assuntos Estratégicos (SAE). Definição da classe média no Brasil. São Paulo; 2012. [acessado 2017 jul 21]. Disponível em: https://cmicro.fgv.br/ sites/cmicro.fgv.br/files/file/Apresenta\%C3\%A7\%C3\%A3o\%20SAE.pdf

26. World Health Organization (WHO). WHO global report on trends in prevalence of tobacco smoking 20002025. Geneva:WHO; 2018. [cited 2018 Sept 4]. Available in: http://www.who.int/tobacco/publications/ surveillance/trends-tobacco-smoking-second-edition/en/

27. Gruber J, Koszegi B. A Modern Economic View of Tobacco Taxation. Paris: International Union Against Tuberculosis and Lung Disease; 2008.

Article submitted 24/10/2019

Approved 11/06/2020

Final version submitted 13/06/2020

Chief editors: Romeu Gomes, Antônio Augusto Moura da Silva 